\title{
BAROK IN SKLADATELJI 20. STOLETJA
}

\author{
Halsey $\mathrm{S}$ teven $\mathrm{s}$
}

Ni dolgo od tega - bilo je pred nekaj leti - ko se je s frazo mnazaj k Bachu ( kar povprek označevala glasba tistih skladateljev, ki so v svojem pisanju uporabljali določene značilnosti kompozicijske prakse poznega baroka. Bila je to pripravna etiketa, ki pa je podobno kot vse take popularne parole zavajala v zmoto. Noben pomembnejši del glasbe 20 . stoletja ne dolguje svoje osnovne naklonjenosti Bachu. Ni ga komponista, ki bi se predvsem zanimal za rekonstrukcijo glasbe neke minule dobe, čeprav si svobodno izposoja njene transformirane elemente pri oblikovanju lastnega izraza.

Glasba, ki je usmerjena $\mathbf{v}$ prihodnost, lahko od časa do časa vrže koristen pogled tudi $v$ preteklost. Videli smo že mnogo primerov. Eden takih je na primer vloga, ki so jo v glasbi 20 . stoletja imeli stari cerkveni modusi, potem ko so jih že zdavnaj opustili in nadomestili z durovskimi in molovskimi lestvicami. Skladatelji Debussy, Ravel, Stravinski, Bartók in mnogi drugi, ki so se jim ti modusi zdeli sugestivni, niso imeli namena, da bi jih uporabljali zato, da bi glasbo modalnega obdobja podvojevali ali jo posnemali, ampak je svobodna uporaba modalnih lestvic osvežila njihove melodije in harmonije. In tako so pisali modalno obarvana dela, ki so se svobodno gibala od enega modusa $k$ drugemu, ne da bi jih pri tem ovirala kakšna tradicionalna modalna teorija.

Razvijanje tonalnosti je bilo seveda eno izmed velikih prispevkov baroka, saj je polifoniji zagotovilo tako harmonsko osnovo kot melodično gradnjo ter obenem omogočilo harmonske okvire, na katere so se lahko napele večje forme. Važen problem, ki je mučil dunajske kromatike 20. stoletja, potem ko so opustili tonalnost, je bilo izgrajevanje velikih form. Nekdo je nekoč dejal, da je v klasični sonati glavna funkcija izpeljave povratek $\mathrm{k}$ toniki; če pa ni tonike, $\mathrm{h}$ kateri bi se lahko vrnili, izgubi forma svoj pomen.

To je morda preveliko poenostavljanje vloge izpeljave. Zdi se mi, da je enako pomembna njena vloga $v$ prikazovanju materiala $z$ najrazličnejših vidikov, torej neka dinamična funkcija v nasprotju s statično v smislu ponavljanja; in ta je še vedno možna, tudi če se opusti tonalnost. Schönberg je to kmalu spoznal. Takšno delo, kot je 4. godalni kvartet, ki je sicer popolnoma serialen, ima kljub temu obliko sonate, ki sloni na motivični jasnosti in izpeljavi. Toda zgodnejša serialna dela Schönberga in 
njegovih učencev, zlasti Weberna, so bile miniature, in Webernove so take tudi ostale.

Eden izmed ponavljajočih se čudežev $v$ glasbi je njena zmožnost, da se nenehno obnavlja. V naglici bi se lahko čudili, čemu niso bile že zdavnaj izčrpane vse možne permutacije zvokov, ki so nam na razpolago. Tu in tam, ko poslušamo novo delo, ki nam je utrudljivo znano, še preden se zaključi, bomo morda za trenutek prepričani, da so zares izčrpane in da ni več možno pisati smiselne glasbe, ne da bi obenem iznašli popolnoma nove estetike.

Tako naziranje seveda vodi $\mathbf{k}$ elektronski glasbi, $\mathbf{k}$ popolni determiniranosti in k vsem najrazličnejšim šolam »aleatorične glasbe, v kateri je sosledje zvokov in sozvočij prepuščeno naključju oziroma svobodni volji izvajalca. Mnogi, ki se ukvarjajo s temi različnimi obrtmi, hoté ignorirajo ali celo zanikajo vsakršno sorodnost svojih postopkov s postopki predhodnikov. Seveda lahko človek po mili volji obrezuje svoje lastne korenine in bo tako početje lahko koristno; če pa poreže prav vse, tvega izgubo stika s svetom okoli sebe.

Ocenitev vpliva baroka na skladanje v 20. stoletju se lahko začne z raziskavo izraza »baročen «. Kaže, da se niti dva avtorja med seboj ne strinjata glede izvora besede in njene aplikacije. V nekem slovarju iz leta 1911 sem bral, da označuje besedo »baročen ( brez kakršnekoli nadaljnje razlage $\mathrm{z}$ izrazoma »slabega okusa; grotesken (. Res je sicer, da je v minulih časih beseda imela pejorativen pomen ne glede na to, ali se je nanašala na nepravilno oblikovanost bisera ali na bizarnost izumetničene arhitekture. Mâle pravi, da se mu zdi, da baročno slikarstvo »prikazuje pomlad triumfalne cerkve, izraženo $\mathrm{v}$ obilju oblik, ekstazi in nepremagljivi potrebi po neskončnem (. ${ }^{1}$ Po D’Orsu je osnovna razlika med klasicizmom in barokom $v$ tem, da klasicizem izhaja iz intelekta, barok pa iz vitalnosti in instinkta. ${ }^{2}$ Za Suzanne Clercx je barok sumetnost gibanja, to je umetnost, $v$ kateri se dinamizem pojavlja kot njena stalna značilnost (.$^{3}$

$\mathrm{V}$ prehodnem obdobju med renesanso in barokom je bila glasba razcepljena med elastično horizontalnost polifonije in nekoliko manj prožno vertikalnost harmonskega pisanja, ki se je izteklo $\mathrm{v}$ princip bassa continua. Ta boj še vedno traja, čeprav s spreminjajočo se težo. Skozi klasično in romantično razdobje je polifonija - z nekaj izjemami - dobila drugoten pomen. Razen nekaj osamljenih stavkov, kot sta na primer finale "Jupiter( simfonije in "Die grosse Fuge», je bilo težišče na homofoniji. Superius se je ločil od spodnjih glasov, bodi zavoljo konture bodi zaradi tonske višine, tako da so le-ti sedaj dobili spremljevalno vlogo. Šele $v$ tem stoletju je nihalo vidno zanihalo v nasprotni smeri.

Baročno obravnavanje disonane se je močno razlikovalo od renesančnega. V zgodnejšem obdobju so bile disonance možne kot prehajalni toni na lahki dobi in kot zadržki na težki.

\footnotetext{
1 Mâle Emile, L'Art religieux après le Concile de Trente, Paris 1932.

${ }^{2}$ D'Ors Eugenio y Rovira, Du baroque, Paris 1936. les 1948 .

${ }^{3}$ Clercx Suzanne, Le Baroque et la musique. Essai d'esthétique musicale, Bruxel-
} 
„Harmonski rezultat kombinacije glasov, ( piše Bukofzer, »so občutili bolj kot zvezo intervalov kakor pa en sam akord. Ta intervalna harmonija renesanse je bila diametralno nasprotna akordni harmoniji baroka. Če je bila harmonija akordno občutena, je bilo možno uvesti disonantno noto kadarkoli, seveda v primeru, da je bil obris akorda kot takega jasen. Bas, ki je v baročni glasbi zastopal akorde, je omogočil zgornjim glasovom, da so svobodneje kot prej oblikovali disonance. Razvez ... se je lahko dosegel $\mathrm{s}$ tem, da se je disonantni glas bodisi spustil bodisi dvignil v najbližji akordni ton. ${ }^{4}$

Bukofzer nadalje obravnava učinek disonantnega tretiranja na harmonski ritem - na )spremembo harmonije na časovno enoto(.

»V hitrem harmonskem ritmu je renesančni skladatelj komaj lahko uporabil kakšno disonanco in zato so vsi tridobni hitri deli izstopali zaradi redkih disonanc. Disonantno tretiranje baročne glasbe pa ni le dovoljevalo hitrega harmonskega ritma, ampak je dalo tudi osnovna tehnična sredstva za afektivni stil recitativa. ${ }^{5}$

Poudarek na basu kot glasu, ki nosi in ustvarja akord, je bila naravna posledica baročnega obravnavanja disonanc. Odnos med basom in superiusom, ki se je sedaj pojavil v obliki »harmonske polaritete«, je obarval vsak aspekt melodije, harmonije in kontrapunkta. Ta odnos je obdržal svojo pomembnost skoraj do današnjih dni in celo dandanes bi komaj lahko rekli, da je izgubil svoj vpliv. Spomnimo se na Brahmsa, ki je najraje presojal skladbo $s$ tem, da se je oziral na odnos med basom in glavno zgornjo linijo, ker je menil, da se vse ostalo lahko prilagodi, če sta ti dve liniji v prepričljivi povezavi. Tudi Hindemith je polagal poudarek na tisto, kar je imenoval »dvoglasno ogrodjec, od katerega je bila odvisna ostala glasbena faktura. ${ }^{6}$ Šele pred kratkim, zlasti med serialnimi komponisti, je prišlo do znatnejše reakcije proti temu principu.

Novi harmonski koncept je $\mathrm{v}$ zgodnjem baroku vodil $\mathrm{k}$ uporabi novih melodičnih intervalov, tako tudi kromatičnih, zvečanih in zmanjšanih. Ritem baroka se je odmaknil od tactusa renesanse, od enakomernega toka udarcev, ki so ga obvladovali, v dveh smereh: v recitativni stil, kjer so bili ritmi pravzaprav ritmi govora $\mathrm{z}$ majhnim poudarkom, in $\mathrm{v}$ mehanično ponavljajoče se utripanje plesne ter stilizirane instrumentalne glasbe. Med tema poloma je baročna glasba uporabljala vse vmesne stopnje ritma.

Če je bila baročna faktura - kljub praksi bassa continua - v glavnem polifona, so baročne forme — vsaj v instrumentalni glasbi - slonele predvsem na aditivnem principu. Glasba za instrumente $s$ tipkami in za lutnjo je uporabljala rapsodične, nekoliko improvizacijske forme: preludij, tokato, fantazijo, intonazione, medtem ko se je koncertantna glasba razvijala $v$ smeri concerta grossa in končno $v$ solo koncert, pri čemer so jo vzpodbujali zakoni antiteze in kontrasta. Ne more biti nobenega dvoma, da je od celotne baročne glasbe ravno concerto grosso imel največji vpliv na glasbo našega časa. Corelliju in njegovim naslednikom, ki so prenesli

\footnotetext{
${ }^{4}$ Bukofzer Manfred, Music in the Baroque Era, New York 1947.

5 Ibid.

${ }^{6}$ Hindemith Paul, Unterweisung im Tonsatz, I. Theoretischer Teil, Mainz 1937.
} 
ustrezne tipe tradicionalne sonate $\mathrm{v}$ concerto $d a$ chiesa in concerto $d a$ camera, se imamo zahvaliti za deli, kot sta Dumbarton Oaks Concerto Stravinskega in Bartókova Glasba za godala, tolkala in celesto.

Za zgodnji ali primitivni barok je značilen pojav čiste instrumentalne glasbe, zlasti sonate, čeprav je ta še vedno imela precej negotovo obliko. V tem obdobju se je prvič posvetila pozornost idiomatskim zmožnostim glasov in instrumentov, kar je do dandanes obdržalo pomembno vlogo v komponiranju. Od renesanse, v kateri so posamezne parte lahko izvajali bodisi instrumenti bodisi pevski glasovi, samo da so imeli potreben obseg, je velik korak do razvoja posebnih stilov in do predstave o glasbi v smislu specifičnih instrumetalnih zvočnosti.

Potem ko je odkril in izrabil razlike $v$ idiomatskih zmožnostih, je baročni skladatelj kasneje odkril še finese, ki so na voljo z izmenjavanjem idiomov samih — s prenašanjem godalnih okraskov na instrumente $\mathrm{s}$ tipkami, z imitacijo godalnih figur $\mathrm{v}$ pihalih itd. Bogastvo instrumentalnega komponiranja $v$ poznem baroku dolguje marsikaj temu odkritju.

$\mathrm{V}$ 17. stoletju je obenem $\mathrm{z}$ razcvetom vokalnih form - opere, oratorija in kantate - prišlo do razvoja instrumentalne glasbe in vzpona koncerta. S poznim barokom, za katerega se lahko reče, da se je v Mannheimu, Parizu in na Dunaju končal med letoma 1740 in 1765 , so bili živi medsebojni vplivi vseh teh form. Prišlo je do zlitja cerkvenega in posvetnega. $\mathrm{V}$ instrumentalni glasbi sta bila sonata in koncert njuna dediča, obenem pa že daleč na poti klasičnega zaporedja »hitro-počasihitrođ namesto konservativne forme petih ali več stavkov. $V$ teh so bili adagii često drobni po obsegu, saj so služili samo kot prehod med glavnimi stavki.

Komorni koncerti so svojo najbolj zamotano polifonijo razkrivali večinoma v preludijih, medtem ko so bili plesi, ki so jim sledili, manj kontrapunktski. Morda bi bilo koristno preučiti že omenjeno delo Stravinskega Dumbarton Oaks Concerto, da bi videli, kakšne so podobnosti prvega stavka z njegovim baročnim predhodnikom.

Roman Vlad citira skladatelja, kakor da bi »priznal(, da delo »sloni na Bachovih Brandenburških koncertih «. ${ }^{7}$ To »priznanje ( sproža zanimivo vprašanje: zdi se namreč, da vključuje občutek neugodja ali zadrege s strani skladatelja. Seveda je dvomljivo, da je Stravinski imel to za "priznanje», ampak je samo obrnil pozornost na nekaj, kar je'bilo že precej jasno: na močan bachovski priokus prvega stavka, katerega struktura in konture imajo mnogo skupnega $\mathrm{z}$ ustreznimi deli v vrsti Brandenburških koncertov.

Tukaj so isti gibčni ritmi, iste linije, ki izhajajo iz akorda in lestvice, ponavljajoči se pedalni ton, ista diatonika. Odnosi med tonovskimi načini so nekoliko bolj statični in taki izmiki iz Es-dura, kakršni se pojavljajo na prvi strani, so samo prehodnega značaja in nimajo vpliva na polariteto tonovskega načina.

7 Vlad Roman, Stravinsky, London \& New York 1960. 


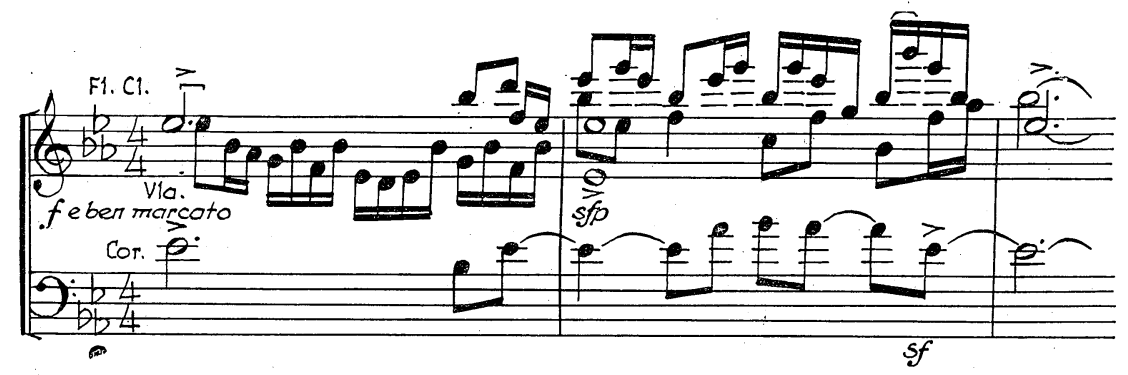

$\mathrm{V}$ delu ni jasne meje med concertinom in ripienom, čeprav pihala in godala le redko izmenjujejo tematsko gradivo. Tudi takrat, ko vsi sodelujejo, so motivi obdelani bolj ali manj antifonalno. Samo v enem obsežnejšem delu stavka se zgodi, da godala skoraj izključno spremljajo, medtem ko je fagotom in rogovom zaupano tematsko delo:

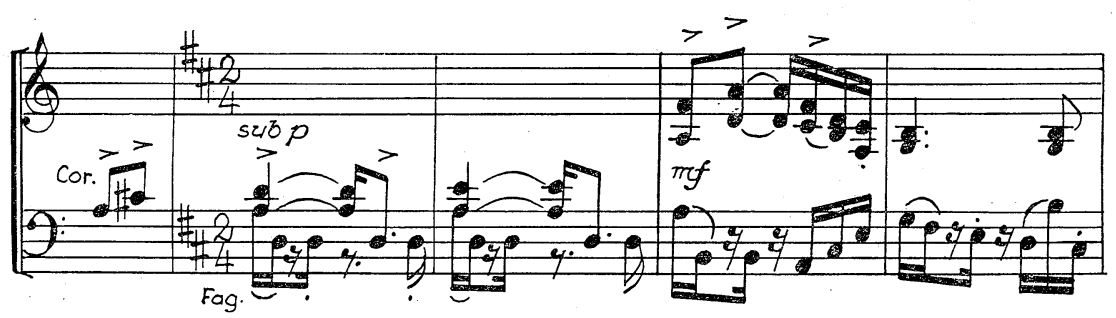

$\mathrm{V}$ obliki fugata $\mathrm{z}$ mnogimi metričnimi spremembami se $\mathrm{v}$ enem izmed naslednjih delov to kompenzira: izvajajo ga izključno godala:

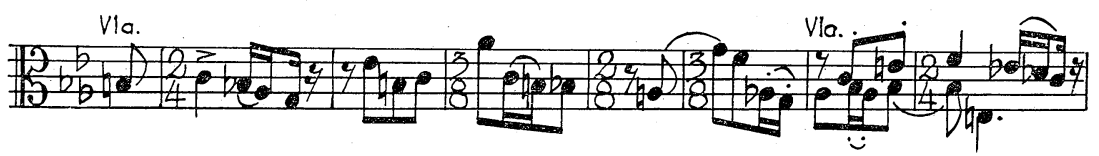

$\mathrm{Ni}$ nobene ponovitve, vendar začetni motivi $\mathrm{v}$ modificirani formi izoblikujejo kodo.

Struktura stavka je torej popolnoma aditivna, pri čemer ponovna uporaba tematskih motivov zagotavlja kontinuiteto. To je $v$ skladu z Bachovo tradicijo, čeprav on sam navadno ne bi uporabil toliko različnih tematskih idej v enem samem stavku, kot je to tukaj storil Stravinski.

Divertimento Béle Bartóka, ki je nastal leto pozneje za koncertom Dumbarton Oaks, prav tako išče inspiracijo v concertu grossu. Nobeno izmed teh del ne pomeni prvega ekskurza skladateljev $v$ forme in stile baroka; zato pa morda najjasneje kažeta njun tovrsten interes.

V nasprotju z Dumbarton Oaks Concertom deli Divertimento izvajalce na concertino ( $\mathrm{v}$ tem primeru godalni kvartet) in na ripieno (godalni orkester) ter se tako bolj približa tradiciji 18. stoletja. Na drugi strani je forma jasna, sonatna, in s te strani kaže na vpliv poznejšega obdobja shematskega izpeljavanja. Delo je nekoliko manj kontrapunktsko kot kompozicija Stravinskega, pri tem pa mu ne manjka polifonskih pri- 
jemov. Dobro je znana Bartókova sposobnost, da poveže najenostavnejšo fakturo s precej zamotano - ne da bi pri tem povzročil vtis heterogenosti.

Prva tematska skupina ima tako kot pri Stravinskem v svojih postopih nekaj poskočnega, kar odkriva njeno naklonjenost baroku. Bartókova tema je sinkopirana, metrum — zanj nenavaden — pa je devet oziroma šestosminski. S sinkopami pridejo kratke note na poudarjene dobe, dolge na nepoudarjene, ker daje skladbi madžarski videz, čeprav metrumi sploh niso madžarski. Razširitev linije $\mathrm{z}$ variiranjem ritmično-melodičnih motivov doseže skladatelj s sredstvi, ki so očitno baročna.

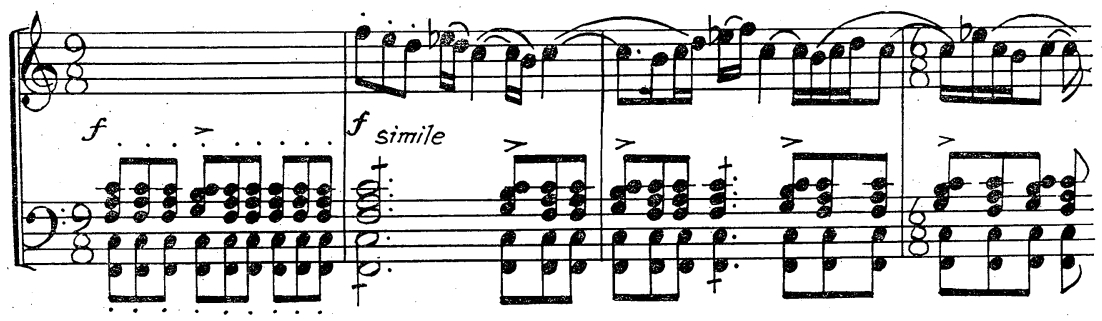

Prvi del izvajajo skoraj izključno tutti. V drugem delu se takt za taktom solo instrumenti vedno $\mathrm{z}$ novim tematskim materialom antifonalno izmenjujejo s tutti.

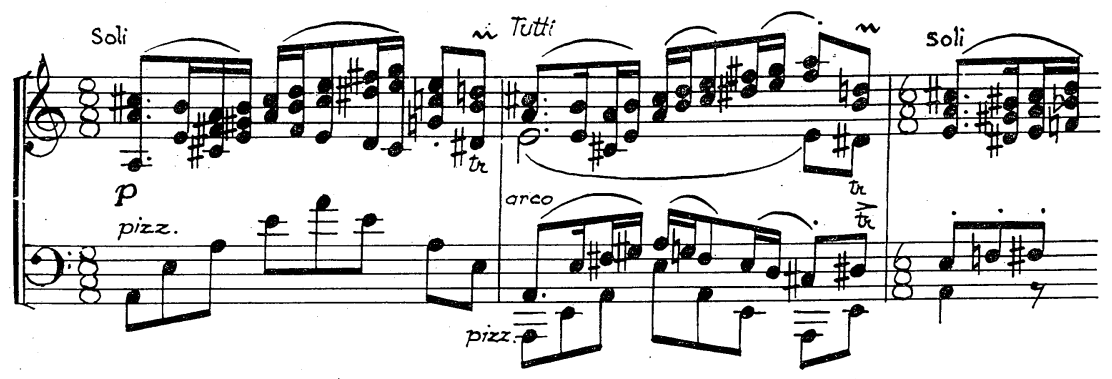

Od tu dalje uporablja $\mathrm{v}$ nasprotju s Stravinskim prijeme, ki so $v$ glavnem značilni za izpeljavo. Čeprav ni jasno ločene reprize, se proti koncu stavka pogosto pojavljajo motivi prve in druge skupine ter tako opravičujejo uvrstitev stavka v sonatno formo.

Imamo torej opraviti z delom, ki po svojem duhu izvira iz concerta grossa poznega baroka, medtem ko je njegova forma odvisna od poznejših vzorov. Isto bi lahko dejali za mnoga dela, ki so nastala $\mathrm{v}$ zadnjih petindvajsetih ali tridesetih letih. Zlasti ritmi - s precejšnjim poudarkom na nenehno ponavljajoče se pulziranje - so vplivali na oblikovanje razmeroma modernega izraza.

Ti ritmi baročnega tipa se pojavijo tudi tam, kjer jih je najmanj pričakovati. Melodična linija, ki služi kot osnova kanonu v št. 18 Schönbergovega dela Pierrot Lunaire (o katerem bomo takoj razpravljali z drugega vidika), je karakteristična, ritmično bi lahko skoraj izvirala iz kakega baročnega koncerta. 


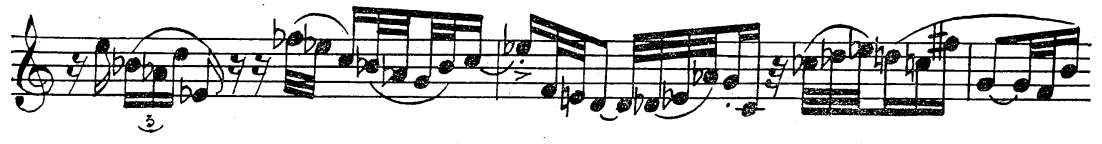

Mislim, da tudi v II. simfoniji Walterja Pistona, v finalu Suite Richarda Donovana ter $v$ mnogih drugih delih zadnjih dveh ali treh desetletij prihaja na dan okus po ritmu poznega baroka.

Antifonalno tretiranje (ki je postalo deloma nujno zaradi razlik v izvajalnih zmožnostih posameznih instrumentov) je bilo, kot smo videli značilno za barok. Skladatelj je lahko zaradi zvočnega kontrasta razdelil izvajalce v večje ali manjše skupine - concertino in ripieno; na drugi strani pa so ga $\mathrm{k}$ temu lahko vodile tudi neenakosti $\mathrm{v}$ izraznih možnostih njegovih instrumentov. Zlasti se to zgodi takrat, ko glasba modulira in ko tisti instrumenti, ki ne morejo slediti, ostanejo zadaj. Znana nam je tako imenovana )terasna dinamika(, $\mathrm{ki}$ je še vedno del klasične orkestralne prakse: medtem ko godala raziskujejo oddaljenejše tonovske načine, pihala molčijo, ker v slednjih ne morejo igrati; vrnitev $\mathrm{v}$ osnovno tonaliteto $\mathrm{s}$ srečno združitvijo vseh pa poudarijo tutti $\mathrm{v}$ fortissimu.

S tem da vzame kot izhodišče idejo antifonalnosti zaradi zvočnega kontrasta in ne toliko zavoljo nuje, porazdeli Bartók v svoji Glasbi za godala, tolkala in celesto godala $\mathrm{v}$ točnem ravnotežju na enake skupine ter jim doda še druge instrumente. Začetna fuga ni antifonalna, vendar je učinek ostalih stavkov odvisen od razporeditve instrumentov: od obeh skupin godal na nasprotnih straneh odra ter od ostalih instrumentov med njima. Čut za smer je važen faktor v zvočnih kombinacijah. Ta skladba, bolj kot katerakoli druga Bartókova nedramatska partitura, je izrazito tridimenzionalna, pri čemer imajo prostorni odnosi velik pomen.

Drugi stavek je v glavnem homofonski, čeprav vsebuje tudi nekaj polifonskih delov, ki sodelujejo pri izgrajevanju forme. Med temi je najbolj važen fugato, ki se pojavi razmeroma pozno in ki s postopnim komprimiranjem teme povzroči občutek neke nuje. Ta prijem je značilen za Bartókovo polifonsko pisanje: namesto da bi obdržal svoj tematski material $\mathrm{v}$ prvotnem sorazmerju, ga nenehno oblikuje, pri tem pa ne žrtvuje njegove identitete ali kontinuitete dela.

Nekatera dela Stravinskega, ki so nastala pred Dumbarton Oaks Concertom, kažejo v tem ali onem smislu njegov dolg baroku. Concerto in $D$ za violino in orkester je blizu baročnim idejam. Naslovi štirih stavkov nudijo ključ za razumevanje: Toccata, Aria I, Aria II, Capriccio. Tu ne gre za prevzemanje starih naslovov, ne oziraje se na njihove zgodovinske implikacije: tri od štirih stavkov preveva duh poznega baroka. Druga Aria, na primer, mnogo dolguje s svojo razkošno okrašeno melodijo, ki je ohlapno vezana na zmerno gibajoči se bas, takim skladbam, kot je Bachova Kromatična fantazija ali pa drugi stavek Italijanskega koncerta. Čeprav se Toccata $\mathrm{v}$ resnici ne sklada s karakterjem baročne solistične skladbe istega imena, za katero so mznačilni rapsodični deli z zadržanimi akordi, bujnimi lestvičnimi pasažami ter lomljenimi figurami na mogočnih pedalnih tonih, ki so se nenadoma izmenjavali s fugiranimi 
odstavki ${ }^{8}{ }^{8}$ pa kljub temu po svojem razpoloženju in fakturi spominja na mnoge Bachove kompozicije za instrumente s tipkami. Tudi njena forma, čeprav na zunaj nekoliko podobna sonatni, je veliko bolj svobodna; razen tega ni v njej izpeljave kot take. Capriccio, ki služi za finale, je poln bachovskih melodičnih figur, razloženih akordov, hitrih lestvic in drugih značilnosti, ki jasno kažejo na njegove predhodnike.

To je barok $\mathrm{v}$ obdobju bassa continua, ko je bilo zanimanje za kontrapunkt majhno, z izjemo odnosa med melodijo in basom. Večji del kompozicije je izključno homofonski. Velja pripomniti, da so njeni vzori očitno Bachova solistična dela za instrumente s tipkami in njegove koncertantne skladbe. Zdi se popolnoma naravno, da je na Stravinskega kot skladatelja za instrumente s tipkami (saj on dela izključno pri klavirju) pri oblikovanju stavka vplival mehanizem pianistove roke; prav tako je bilo pričakovati, da bo bolj doma $\mathrm{v}$ baročni glasbi za instrumente $\mathrm{s}$ tipkami kot pa $\mathrm{v}$ ansambelski glasbi, ki so jo $\mathrm{v}$ zgodnjih tridesetih letih le malo izvajali.

Roman Vlad pravi o tem delu naslednje:

)Čeprav ni nobenega namiga, da bi si kaj dejansko izposodil, bi bilo pravično, če rečemo, da aluzij - če že so - na pretekla dela ne uporablja za groteskne, parodne efekte. Prav nasprotno: zdi se, da mu služijo kot sredstvo za izražanje tihega hrepenenja za polno ekspresivnostjo, ki jo je nekoč imela glasba. Zares,... Stravinski opusti svoj odnos upora proti romantizmu in se preda nostalgičnemu rechercher $d u$ temps perdu. ${ }^{9}$

Seveda lahko vsak $v$ skladu s svojim osebnim tolmačenjem razlaga glasbo, kakor hoče. „Tiho hrepenenje za polno ekspresivnostjo, ki jo je nekoč imela glasbac je lahko, ali pa tudi ne, vzpodbudilo Stravinskega, da je skomponiral Violinski koncert; bolj verjetno, da ni. Vsaj meni je to manj izraz domotožja za minulimi časi in bolj zavestna in hotena vaja $\mathrm{v}$ uporabi starih form za nove izrazne namene.

Duo Concertant za violino in klavir ima mnogo skupnih značilnosti z Violinskim koncertom. Zelo pogosto lahko opazimo, če pregledujemo seznam del kakega skladatelja, da ga momentum, ki se je akumuliral ob skladanju enega dela, žene skozi drugo delo istega ali podobnega značaja, preden se njegova pozornost usmeri drugam. Tukaj so močne podobnosti glede strukture, karakterja in stila. Namesto Toccate je Cantilena; dve Eklogi nadomestita obe Ariji; Gigue prevzame mesto Capriccia; na koncu je še Dithyramb, ki v Violinskem koncertu sicer nima paralele, a je po svojem karakterju zelo podoben drugi Ariji.

Baročne značilnosti imajo nekaj časa važno vlogo $\mathrm{v}$ delu Igorja Stravinskega. Tako bi med drugim lahko preučili na primer Koncert $z a$ dva klavirja in Simfonijo psalmov. Ker se bomo vrnili k Stravinskemu še enkrat v zvezi z njegovo serialno glasbo zadnjih let, se ozrimo $h$ glasbi Paula Hindemitha, ki se je morda bolj kot kak drug pomemben novejši skladatelj okoristil s kompozicijskimi prijemi poznega baroka.

8 Bukofzer, op. cit.

9 Vlad, op. cit. 
Hindemithove najbolj zgodnje partiture, ki so nam dostopne, kažejo avtorja kot skladatelja $s$ tekočo kontrapunktsko tehniko, doma $v$ fugi in ostali imitacijski polifoniji kakor tudi $v$ variacijski tehniki. Njegov tematski material - celo $\mathrm{v}$ mladostnih delih - se nagiba $\mathrm{k}$ »motoričnostic concerta grossa, )motoričnosti«, ki je bila zares značilna za precejšen del glasbe dvajsetih in tridesetih let tega stoletja. Bilo bi naivno, če bi dejali, da dolguje Hindemith več baroku kot drugim obdobjem glasbene zgodovine. On je pravi eklektik, ki si za dosego svojih ciljev sposoja, kar mu pride pod roko, in vendar zna napraviti te »izposoje (, kot da bi bile njemu lastne.

Tako ga leta 1922, na začetku njegove kariere, vidimo, kako ustvarja dela, ki so po svojih tehnikah in vidikih zelo različna: 3. godalni kvartet s fugiranim začetkom in potezami bitonalnosti (principa, ki se ga je kasneje izogibal), Pihalni kvintet, ki je svobodno kromatičen in tonalno protisloven, dalje, nekoliko brahmsovska 1 . sonata za violo in klavirska suita »1922 (, s svojim tevtonsko obteženim jazzom. Z letom 1925, s 4. godalnim kvartetom, pa so se ti elementi zlili $\mathrm{v}$ znani »Hindemithov stilk, po katerem kljub modifikacijam ni bilo nadaljnjih stilističnih neskladij.

Prvi stavek 4. kvarteta je značilen za »Hindemithov stilı. Lahko ga imamo za nekakšno trojno fugo, katere prvi del eksponira in na široko razvije krepko »motorično( temo:
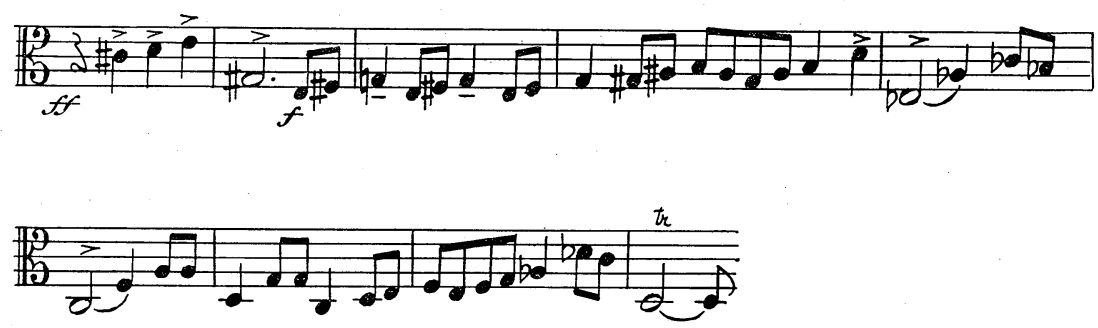

Hindemithove fuge redko uporabljajo običajne intervale imitacije; v obravnavani ekspoziciji si štirje vstopi sledijo $v$ naslednjem vrstnem redu: cis, e, gis in a. Ni nobenega kontrasubjekta, čeprav se motivi iz asociativnega gradiva neredno pojavljajo med procesom obdelave.

Srednji del stavka prinese popolno spremembo razpoloženja. Istočasno eksponira in razvije dve temi:

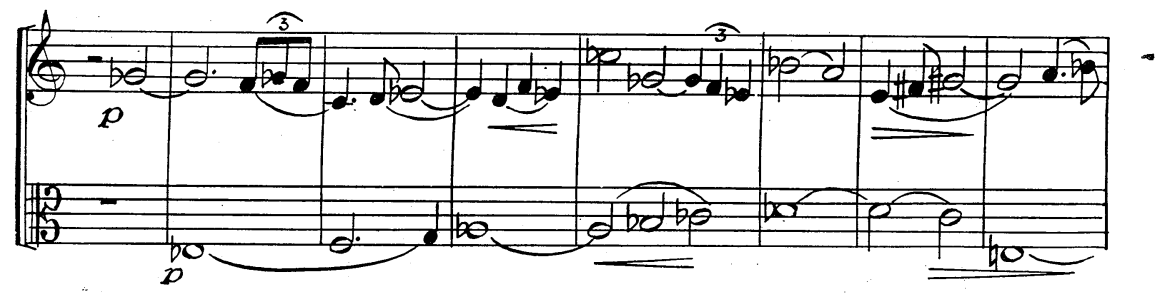


ki (z ostalimi motivi) polagoma obnovita hitrost in značaj prvega dela, ko se po nekaj predhodnih ponovitvah osnovnega motiva pojavi glavna tema $\mathrm{v}$ povezavi z ostalima dvema. Koda je posvečena samo prvi temi.

Tukaj imamo $v$ malem opraviti $z$ naziranjem, ki ga je Hindemith poslej obdržal v svojem skladanju. Če bi bili potrebni nadaljnji dokazi za njegov naslon na barok, bi lahko prelistali partituro in našli, da sestoji zadnji stavek iz passacaglie $\mathrm{z}$ zaključnim fugatom. Melodično razkošje, bujnost fakture, sila ritmov, vse to priča o njihovem izvoru.

Skoraj dvajset let je minilo, preden je Hindemith napisal naslednji godalni kvartet. Če bi ne poznal glasbe, ki jo je ustvaril $v$ tem obdobju, bi človek pričakoval bistvene razlike; leta 1925 je bil skladatelj komaj trideset let star, medtem ko je bil 1943 blizu petdeset. In vendar se zdi, da je $\mathrm{v}$ času od svoje mladosti do zrelosti samo okrepil svoja načela in in utrdil svojo tehniko. V 4. kvartetu se je zadovoljil s tem, da je vrsto stavkov, ki so si bili po značaju kontrastni in ki jih ni vezal noben skupen material, postavil drugega poleg drugega. V 5. pa se je ukvarjal z vseobsežno organizacijo, tako da je lahko tisto, kar ni povedal v prvih stavkih, zaključil v finalu.

Kot 3. začenja tudi 5. kvartet $\mathrm{s}$ počasnim fugatom na kromatično temo. Ekspozicijo sestavlja pet vstopov (na d, a, gis, c in d) skupaj z razširjeno kadenco.

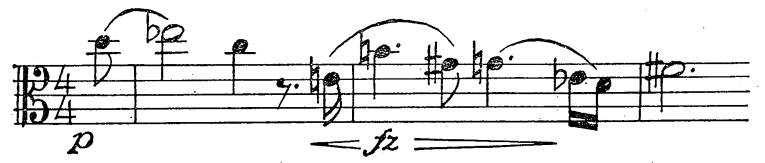

$\mathrm{V}$ nadaljnjem delu stavka pride samo še do petih popolnih nastopov teme. Tako je stavek nepopoln in zato nekakšen razširjen uvod $\mathrm{k}$ živahnemu sonati podobnemu delu, ki sledi. Tudi tukaj je forma okrnjena; jasno nakazani ekspoziciji dveh tematskih kompleksov
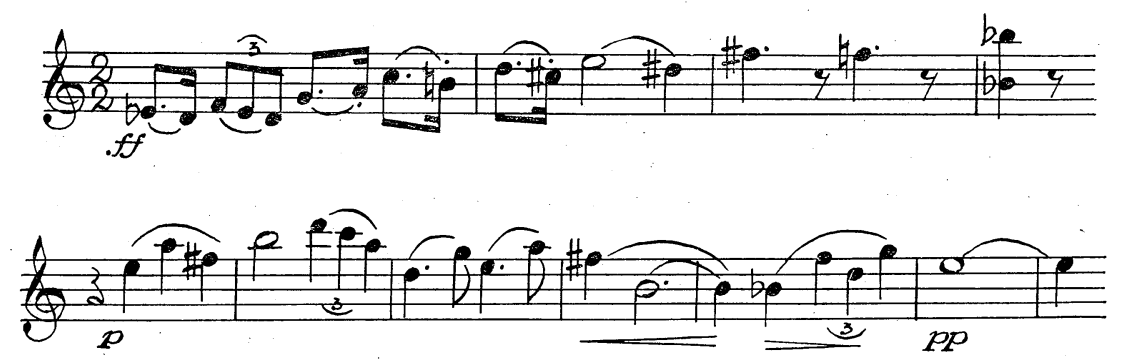

sledi obsežna izpeljava. Ni pa nobene prave reprize, čeprav se stavek zaključi s polnim E-durovim trozvokom.

Tretji stavek predsavljajo variacije na šesttaktno temo:

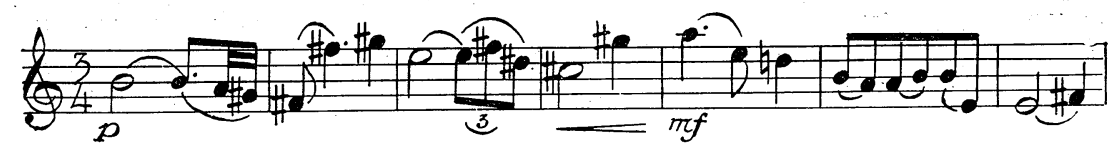


Sledijo štiri variacije, ki se po karakterju med seboj močno razlikujejo. To je prvi stavek, za katerega bi lahko rekli, da je popoln, čeprav pomenijo - z drugega vidika - variacije formo, ki je odprta in ki se lahko nadaljuje $v$ nedogled, ne da bi pri tem vzbudila potrebo po zaključku.

Zadnji stavek je tisti, v katerem doseže Hindemithova uporaba zamotanosti baročne polifonije svoj višek. Zdi se najprej, kakor da bi pripravljal še eno sonati podobno formo, saj spominja začetna tema po svoji konturi na temo fugata prvega stavka:

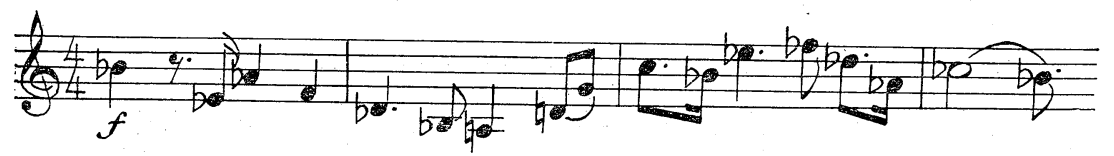

To je šele prvi namig, ki nakazuje ponovno uporabo starega materiala, vendar pa skladatelj za nekaj strani odloži potrditev svoje namere. Pred nami eksponira dva drobna motiva:
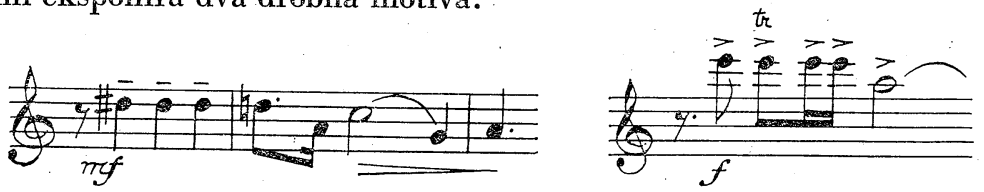

Nato vzame prvega in začne z glavnim delom stavka, kar je nekdo nekoč imenoval )superfugo(. Njen začetek je enostaven: štirje vstopi (na e, b, fis in e) in kratka obdelava. Sledi obsežen stretto na fugino temo, potem pa skladatelj postopoma vnaša $\mathrm{v}$ tkivo ves prejšnji material: temo prve fuge, obe temi drugega stavka, temo variacij in končno, otvoritveno temo finala, s čimer zgradi širok vrhunec in quasikadenco. Razpoloženje se nenadoma spremeni s kodo, ki sloni na drugem izmed obeh prej omenjenih motivov s citati iz ostalega tematičnega materiala.

Fuga je imela razmeroma nepomembno vlogo $v$ postbaročni glasbi vse do 20. stoletja. Oživljeno zanimanje zanjo imamo lahko za znak interesa za barok. Kaže, da so fugo na eno samo temo - za razliko od zgodnejšega politematskega ricercara - v poznem 17. in zgodnjem 18. stoletju razvili taki skladatelji, kot so bili Pasquini, Casini in Bencini. Potem je fuga v Italiji upadla. Domenico Scarlatti, ki bi bil lahko podedoval tradicijo, je kazal malo zanimanja zanjo. Njegovim fugam manjka samostojnost kontrapunktskega pisanja in njegove sonate za cembalo jasno anticipirajo homofonijo klasicizma.

Kot bi bilo pričakovati, sloni velik del fug 20. stoletja na Bachovi tehniki. Tudi tukaj gre morda za vprašanje sorodnosti: Bachove fuge so znamenite in $\mathrm{v}$ mnogočem sploh višek fuge. Zato je naravno, da služijo za vzor.

V podrobnostih Hindemithove fuge niso nujno bachovske. Ludus Tonalis raziskuje na primer različne tipe oblikovanja fuge, vendar brez kontrasubjektov, brez tonalnih odgovorov in $\mathrm{v}$ vrsti primerov, $\mathrm{s}$ poudarkom na kombinacijah tem, na kontrapunktskih prijemih inverzije in 
avgmentacije in, $\mathrm{v}$ eni fugi, na popolnem raku prve polovice $\mathrm{v}$ drugem delu.

Bartokovih fug je razmeroma malo, čeprav je najti fugato odstavke $v$ vrsti njegovih del. ${ }^{10}$ Edini popolni stavek $v$ obliki fuge je otvoritveni Andante v Glasbi za godala, tolkala in celesto. Sloni na eni sami kromatični temi s štirimi različnimi motivi, ki imajo nato pomembno vlogo v naslednjih stavkih. Imitacije nastopajo izmenoma za kvinto više oziroma niže: a-e-d-h-g itd., z viškom na es, ko se fuga obrne nazaj proti začetku z obrnjeno temo.
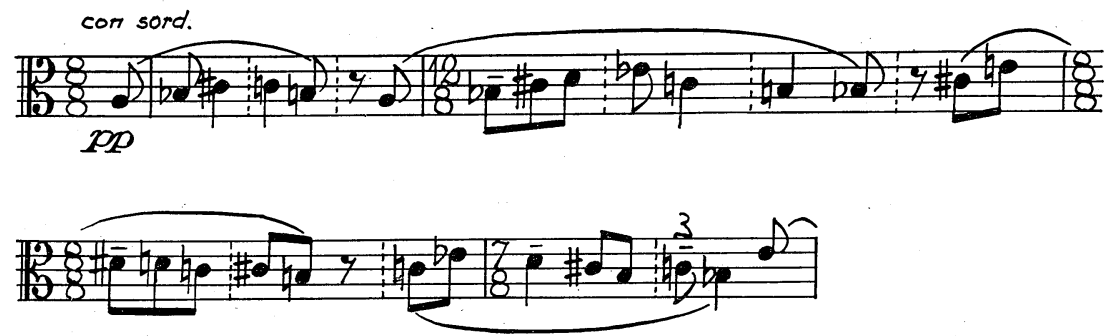

„Izredna ekonomičnost stavka se kaže $\mathbf{v}$ odsotnosti kakršnegakoli materiala, ki ne bi bil del teme. Ni nobenega kontrasubjekta, nobenih )Svobodnih( kontrapunktskih linij. Celotno tkivo je stkano iz ene same niti. Seveda pride do intervalnih sprememb in drugih modifikacij, katerim so Bartókove teme $\mathrm{v}$ fugah normalno podvržene, namreč do skrajšav in podaljšav. Kljub temu pa lahko vsaki noti sledimo nazaj v samo temo.

Posledica tega je skoraj brez primere zgoščen stavek; šest in pol minut, kolikor traja, predstavlja en sam crescendo $\mathrm{k}$ vrhuncu, dokler zopet ne izzveni $v$ tišino.( ${ }^{11}$

Ta enovitost je skoraj enkratna $v$ novejši glasbi, pa tudi sicer jo je Bartók le redko dosegel.

Ostala sredstva baročne polifonije - kanon, obrnitev, avgmentacija, deminucija, rak itd. (ki so seveda obstajala že prej, a jih je barok okrepil) - so se tako ali drugače večinoma vključila v sodobno prakso. Bilo bi skoraj nemogoče najti kakršnokoli novejšo partituro, $v$ kateri to ali ono bi ne imelo kakšne vloge. Tehnična prijema obrnitve in raka sta bistveno prispevala $\mathrm{k}$ )tehniki komponiranja z dvanajstimi toni( ter omogočila, da se osnovni material serialne skladbe lahko prikaže $\mathbf{v}$ štirih različnih oblikah, brez transponiranja ali kakšnega drugega manipuliranja.

Stravinskega Dvojni kanon za godalni kvartet, ki obsega eno stran in je bil napisan v spomin Raoula Dufyja (1959) se zdi domiseln, dokler ga pozorno ne preučimo. Notna slika - brez taktnic ter z notnim črtovjem, ki v spodnjih dveh glasovih kasneje začne in prej konča - ga dela navidezno avantgardnega. Vendar se pokaže, da je delo sterilno, saj mehanično obdeluje dvanajsttonsko vrsto, ki jo ob spreminjajočih se intervalih

${ }^{10}$ Npr.: Suita št. 2, Čudežni mandarin, 4. in 5. kvartet, Divertimento, Koncert za orkester itd.

${ }^{11}$ Stevens H., The life and music of Béla Bartók, New York 1953, rev. ed. 1964. 
imitira $\mathrm{z}$ rakom in obrnitvami; vse fraze so enako dolge, sozvočja ne vedno ravno posrečena. ${ }^{12} \mathrm{~V}$ primerjavi z dvojnim kanonom v št. 18 Schönbergovega dela Pierrot Lunaire je to dolgočasna, dlakocepska vaja, tako da komaj občudujemo skladatelja, ki je menil, da je vredna objave.

Schönberg je vsaj s tehničnega stališča veliko zahtevnejši. Klarinet, ki ga tri dobe pozneje kanonično imitira pikolo, in violina, ki jo štiri dobe kasneje imitira čelo, igrata dvojni kanon, ki se sredi desetega takta obrne proti svojemu začetku. Istočasno igra klavir ob dodanih imitacijsko-kontrapunktskih glasovih avgmentirano verzijo kanona, ki ga izvajata klarinet in pikolo. Ko prispe do točke, na kateri so se ostali obrnili, ti med tem dosežejo izhodišče in stavek se zaključi. Klavirju je dodana tudi Sprechstimme, deloma péta deloma govorjena, ki se quasi imitacijsko razvija, ne da bi se pri tem vrnila na svoj začetek. Seveda bi bilo težko pričakovati, da bi bile te in take vaje jasne poslušalcu. Rakove forme so samo izjemoma dojemljive ušesom, ker je njihov ritem obrnjen. Vendar je razmeroma enostavno oblikovati take ritmične formule, ki bodo iste tudi v raku, se pravi palindromske ritme, kot jih kaže naslednja melodična linija. Tukaj je vsak takt palindromski; zategadelj je rakovo formo možno identificirati.
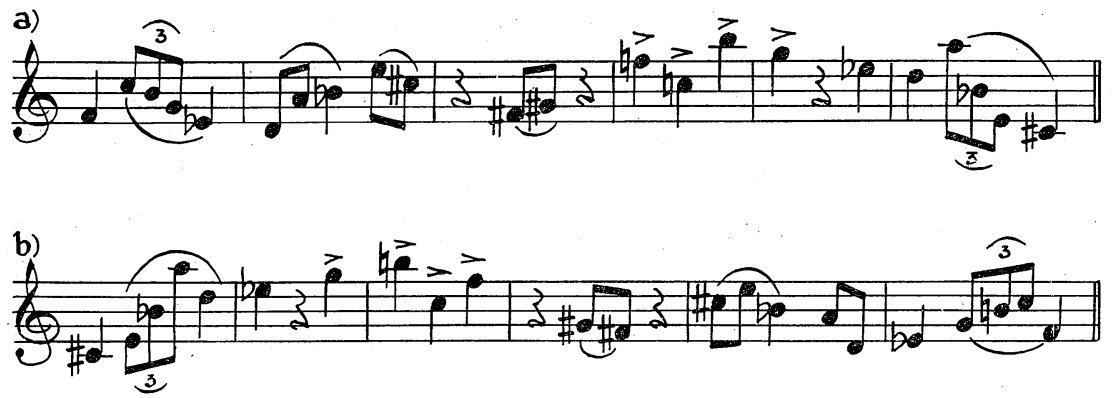

Odnos med višino posameznih tonov je manj pomemben. Podobnost bi bila skoraj enaka, če bi bili toni popolnoma drugi, samo da bi bili seveda ohranjeni ritmi.

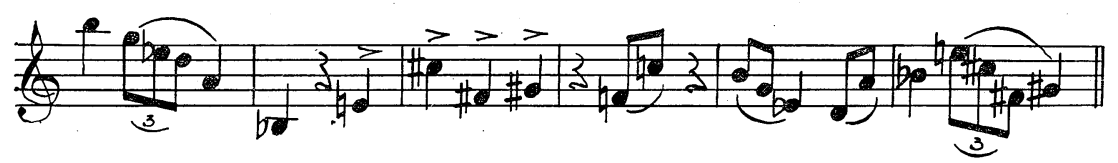

Punktirani ritmi, anakruze in podobne neenake figure popolnoma spremene svoj značaj, ko jih obrnemo; tako je rak le redko dojemljiv ušesu.

Zato je optimistično pričakovati, da bo poslušalec vedel, kaj se $\mathrm{v}$ resnici $\mathrm{s}$ tehničnega stališča dogaja $\mathrm{v}$ kompoziciji Der Mondfleck. Večina ritmov je tako komplicirana, da bi jih težko zaznali, ko so zaigrani nazaj. Mislim, da to ni važno. Ne verjamem, da bi se skladatelj moral ozirati na

${ }^{12} \mathrm{Npr}$. tisto mesto $\mathrm{v}$ drugem sistemu, kjer violina, viola in čelo igrajo ais, druga violina pa eis-cis. 
poslušalčevo zmožnost razreševanja njegovih metod, dokler se mu zdi glasba, ki jo piše, smiselna.

To je seveda preddodekafonsko delo, vendar preroškega značaja za nadaljnji razvoj. Govoril sem že o uporabi baročnih polifonskih sredstev v dvanajsttonskem skladanju. C̆e bi prostor dovoljeval, bi lahko šli v detajle teh procesov - toda to bi pomenilo novo obsežno poglavje. Skladatelji, ki sedaj sledijo Webernu, pomenijo v nekem smislu naključje, če že ne anomalijo. Okoli leta 1590 je florentinska Camerata pod vodstvom grofov Bardija in Corsija napadla renesančno glasbo ter postavila teorije, na podlagi katerih je bilo sedaj treba skladati. Navadno vzamemo teoretiziranje v okviru Camerate kot začetek baročne dobe.

Od takrat naprej se je vrstni red obrnil; skladatelji so pisali glasbo in prepuščali analitikom, da so iz samih del izvajali teorije. V zadnjih nekaj letih pa zopet najdemo skladatelje najbolj »naprednih« tendenc, kako razglašajo teorije pred glasbo. Morda smo $\mathrm{v}$ tem smislu zaključili krog in smo zopet na pragu nekega novega baroka.

Vendar je ena velika razlika. Publika, ki razume in uživa $v$ delih teh )naprednih ( skladateljev, je zares maloštevilna. Svoje poslušalce so namreč skladatelji pustili zadaj.

)Usoden prepad med skladateljem in poslušalci, ki je značilen za moderno glasbenn življenje, ( piše Bukofzer, ${ }^{13}$ »ni obstajal $v$ baročnem obdobju. Skladatelji so samo po sebi umevno pisali $\mathrm{v}$ jeziku, ki je bil takrat ,moderen'. Niso se bali ..., da bi bil njihov genij morda priznan šele takrat, ko bi bili $v$ grobu že toliko časa, da bi jih proglasili za ,klasike'. Aristokrati in patriciji so imeli dovolj tehničnega znanja, da so lahko šli vštric z glasbenimi novostmi svojega časa . . . Ni se zgodilo, da bi skladatelji pisali za ,siroko' publiko, niti jih ni mučila ideja, da bi skladali za večnost ... Ravno zato, ker je Bach pisal ,za današnjo rabo,' kolikor je mogel dovršeno in ,umetelno,' je skomponiral glasbo, ki ni pripadala samo eni dobi, ampak vsem časom.৫

Naj bo vzrok že kakršenkoli, skladatelj nima več tako tesnega stika s svojo publiko, kakršen je bil sbičajno v baroku. Če bi bil ta stik spet možen, bi bil za skladatelja bolj koristen kot kakršnokoli število pohvalnih kritik in kot je odobravanje majhne skupine prijateljev. V takem primeru bi - če nič drugega - lahko komaj ostal vzvišen nad potencialnimi potrošniki njegove glasbe in trosil neprebavljive slaščice $z$ višin v upanju, da se bo na koncu odkrilo, da so okusne.

\section{SUMMARY}

Free borrowing and use of transformed elements of the music of past periods when forming contemporary music enables musical art, while incorporating the new, to maintain the continuity of its development; otherwise music risks losing contact with the world around. Many characteristics of baroque composition have found application in a number of $20^{\text {th }}$ century works: rhythm, polyphonic texture, the additive principle of formal construction, the use of idiomatic idiosyncrasies of individual

\footnotetext{
${ }^{13}$ Op. cit.
} 
instruments and the interchange of these idioms, the harmonic polarity between bass and superius, called by Hindemith the stwo-voice framework «, etc. There can be no doubt that out of the whole of Baroque music it is the Concerto Grosso which has had the greatest influence on the music of today. Thus the contours and structure of Stravinsky's Dumbarton Oaks Concerto have much in common with corresponding parts in a number of the Brandenburg Concertos. We can also trace Baroque characteristics in some of Stravinsky's other works - in Concerto in D, Concerto for Two Solo Pianos and in the Symphony of Psalms. The Divertimento of Béla Bartók also seeks inspiration in the concerto grosso, in dividing the performers into concertino and ripieno and in baroque rhythms, which appear even in such a work as Schönberg's Pierrot Lunaire. Antiphonality is intensified in Bartók's Music for Strings, Percussion and Celesta serving him as a departure for the achievement of sonorous contrasts. Hindemith owes much to the Baroque. His treatment of the fugue is typical of the characteristic "Hindemith style« which has essentially remained unchanged but seems to have consolidated from youth to maturity. A revived interest in the fugue may be considered a sign of interest in the baroque, as is also interest in other features of baroque polyphony - canon, inversion, augmentation, diminution and retrogression, etc., which have all been incorporated in contemporary compositional practice.

If the use of such features as these becomes an aim in itself so that music loses its point, we come to that abyss between composer and listener which distinguishes contemporary musical life. The baroque composer wrote as a matter of course in an idiom which was »modern « and comprehensible at the time. He wrote for the day but as elaborately and »artificially ( as he could. The audience had sufficient technical knowledge to keep abreast with the musical innovations of the time. Today, for whatever reason, a »progressive « composer no longer has the close contact with his audience that was usual in the Baroque age. If it were once more possible it might be more beneficial to the composer than any number of laudatory reviews or the approbation of a small group of friends. In such a case, at least, he could hardly remain aloof from the potential consumers of his music and scatter indigestible tidbits from a height, in the hope that they would ultimately be found palatable.

The quotations are reprinted by kind permission of:

Bartók: Universal-Edition AG, Wien; Boosey \& Hawkes, London \& New York

Hindemith: B. Schott's Söhne, Mainz

Stravinsky: B. Schott's Söhne, Mainz

Schönberg: Universal-Edition AG, Wien 